\title{
ß-Sitosterol: An Antibacterial Agent in Aquaculture Management of Vibrio Infections
}

\author{
Lokesh Ravi* (D), Shabari Girish (D), M. Harshini ${ }^{(D)}$ and B.K. Anirudh Sreenivas $(\mathbb{D}$ \\ Department of Botany, St. Joseph's College (Autonomous), No.36, Lalbagh Road, Bengaluru - 560007 , \\ Karnataka, India.
}

\begin{abstract}
This study aims at investigation of antibacterial property of Parthenium hysterophorus against aquatic bacterial pathogens and to identify the key bioactive compound of the same. Antibacterial activity of the crude extracts confirmed that chloroform extract PHC has strong antibacterial activity against aquatic pathogens V.anguillarum and V.harveyi with $16 \mathrm{~mm}$ and $15 \mathrm{~mm}$ ZOI at $1 \mathrm{mg} /$ well concentration. The crude extracts were subjected for GC-MS analysis to identify the secondary metabolites. PHC was subjected to silica-gel column chromatography to separate the individual phytochemicals. PHC was separated into 9 fractions, among which Fraction No.2 demonstrated significant antibacterial activity against V.anguillarum and V.harveyi with $19 \mathrm{~mm}$ and $17 \mathrm{~mm}$ ZOI at $10 \mu \mathrm{g} / \mathrm{well}$ concentration. Fraction No. 2 was identified to be $\beta$-sitosterol based on mass spectrometry analysis and fragmentation analysis. In-silico protein ligand docking demonstrated that $\beta$-sitosterol has highest affinity to inhibit dihydrofolate reductase (DHFR) enzyme with $-10.10 \mathrm{Kcal} / \mathrm{mol}$ binding energy. This prediction was further validated using molecular dynamic simulation for $20 \mathrm{~ns}$. Based on these computational analyses, it was proposed that $\beta$-sitosterol exhibits antibacterial activity via inhibition of DHFR enzyme. $\beta$-sitosterol is a well known nutritionally valuable compound that reduces cholesterol levels in humans. It is also been used as supplement feed to increase the nutritional value of cultured fishes. $\beta$-sitosterol has also been proven to have positive effect in growth and reproduction of cultivated fishes. Findings of this study strongly suggest the usage of $\beta$-sitosterol in aquaculture, as nutritional supplement and also as disease control agent to prevent and control fish diseases caused by Vibrio species.

Keywords: Parthenium hysterophorus, Sitosterol, Vibrio anguillarum, Vibrio harveyi, DHFR Inhibition
\end{abstract}

\footnotetext{
*Correspondence: lokesh.ravi@sjc.ac.in; +91-8098945561
}

(Received: August 16, 2020; accepted: December 03, 2020)

Citation: Ravi L, Girish S, Harshini M, Sreenivas BKA. $\beta$-Sitosterol: An Antibacterial Agent in Aquaculture Management of Vibrio Infections. J Pure Appl Microbiol. 2020;14(4):2699-2714. doi: 10.22207/JPAM.14.4.48

(C) The Author(s) 2020. Open Access. This article is distributed under the terms of the Creative Commons Attribution 4.0 International License which permits unrestricted use, sharing, distribution, and reproduction in any medium, provided you give appropriate credit to the original author(s) and the source, provide a link to the Creative Commons license, and indicate if changes were made. 


\section{INTRODUCTION}

Aquaculture plays a key role in India's economy, as it is the second largest producer in the world. Bacterial infection in fishes causes a great loss in the fish cultivation. Vibrio genus is a group of gram-negative bacillus organisms that are popularly known for their pathogenic impact in aquaculture. The Vibrio species bacteria's causes a serious disease called vibriosis, which causes a major loss in the aquaculture economy. Vibrio anguillarum is a polarly flagellated, comma shaped bacteria, that mainly causes vibriosis in many fish cultures ${ }^{1}$ bioluminescent bacteria and their fish hosts remain unidentified and untapped for potential biomedical applications. In this study, 51 out of 60 marine fish samples purchased from selected public seafood markets in the Philippines were found to be associated with bioluminescent bacteria. Purified bioluminescent bacterial colonies isolated from the intestine and skin of the fish samples were screened for antibacterial activity against strains of hospital-acquired pathogens, also known as 'nosocomial' pathogens, Staphylococcus aureus and Klebsiella pneumoniae. Membrane and cytosolic fractions from 4 bioluminescent bacterial isolates, designated here as strains ADMU-AUF-01 to -04 , isolated from Lagocephalus spadiceus (half-smooth golden puffer fish. Vibrio harveyi is a causes several types of diseases such as gastroenteritis, eye lesions and vasculitis in shrimps and other fishes ${ }^{2}$. As the antibiotics currently used in aquaculture fisheries are becoming ineffective due to development of drug resistance, it is time of the hour need to identify and employ an effective alternative antibiotic of natural origin.

Due to development of resistance and due to undesirable side effects of chemically synthesized antibiotics drugs, pharmaceutical industries are currently focusing on identifying suitable alternative from natural sources, mainly from plant and microbial secondary metabolites. The current demand is to use natural product secondary metabolite as lead molecule to develop effective and specific bioactive derivative molecules that possess least desired side-effects. Plant phytochemicals have been a major source of bioactive compounds from ancient times, as evident from Ayurveda, Siddha and other traditional medicinal practices ${ }^{3,4}$ screening the phytogenic chemical compounds, and to assess the alkaloids present in the $\mathrm{E}$. intermedia to prove its uses in Pakistani folk medicines for the treatment of asthma and bronchitis. Antioxidant activity was analyzed by using 2,2-diphenyl-1picryl-hydrazyl-hydrate assay. Standard methods were used for the identification of cardiac glycosides, phenolic compounds, flavonoids, anthraquinones, and alkaloids. High performance liquid chromatography (HPLC).

Weed plants are commonly regarded as biological wastes and are burned and buried to control their fast growth and spread. However, several industrial applications and uses of these weed plants are being studied by researchers largely. Parthenium hysterophorus is a well known weed plant, belonging to Asteraceae family, possessing characteristic fleshy leaves and white star-like flowers ${ }^{5}$. Scientists have reported the medicinal benefits of Parthenium hysterophorus in several in-vitro and in-vivo studies ${ }^{6}$. Parthenium hysterophorus is proven to have antipyretic, antidiarrhea, neuroprotective, antimicrobial, antidiabetic, antiparasitic activities and antiheaptic amoebiasis ${ }^{7-9}$. Tribal civilizations have used Parthenium hysterophorus an anti-inflammatory agent, remedy for eczema, skin rashes, herpes, cold, and gynecological disorders ${ }^{10}$. Parthenium hysterophorus is also a well known source of antibacterial phytochemicals.

Sitosterol also known as Beta-Sitosterol, is a phytosterol secondary metabolite reported to be present commonly in many plants including Parthenium hysterophorus. It has a characteristic odor with hydrophobic properties and waxy powder like appearance, and is widely present in many plant species and commonly found in vegetable oils, nuts, $\&$ avocadoes ${ }^{11}$ vapor pressures of cholesterol, ergosterol, $\beta$-sitosterol, and stigmasterol were measured by an isothermal Knudsen effusion method. The vapor pressure correlations were fitted to the following equations: cholesterol $\ln (\mathrm{p} / \mathrm{Pa}$. $\beta$-Sitosterol has been reported to possess several biological activities in pharmaceutical prospects such as anticancer, anti-inflammatory, androgenic, antioxidant, antidiabetic, angiogenic, anorexic, antifeedant, antileukemic, chemoprotectant, neucroprotective activities etc. ${ }^{12-14}$; it aids in treatment of Benign Prostatic hyperplasia $(\mathrm{BPH})^{12}$; It has been reported to prevent hair loss and has hair-regeneration 
property even in case of bald scalp ${ }^{13}$; It is reported to increase LDL levels and reduce HDL levels in humans. In regards to veterinary and fish applications; it is used as anabolic steroid to induce cattle growth ${ }^{15} ; \beta$-sitosterol supplementation greatly promotes successful growth of larvae in to adult in case of Penaeus japonicus; positive regulation on fish reproduction/fertilization as proven on fresh water organisms such as Salvelinus fontinalis and Carassius auratus ${ }^{16,17}$ the predominant plant sterol in pulp mill effluent, has previously been shown to decrease plasma sex steroid and cholesterol levels and in vitro gonadal steroid production in fish. In this study, male brook trout (Salvelinus fontinalis. These reports suggest that $\beta$-sitosterol has significant value as a nutritional supplement and also as valuable medicinal compound for both human and animal applications.

In this current study, Parthenium hysterophorus was investigated for antibacterial activity against aquatic bacterial pathogens and the key antibacterial compound in it was identified to be $\beta$-sitosterol via in-vitro bioassay and analytical chemistry methods. The mechanism of action of sitosterol was predicted to inhibit dihydrofolate reductase (DHFR) enzyme, via in-silico portien-ligand docking and molecular dynamic simulation studies.

\section{MATERIALS AND METHODS Plant Material and Extraction}

The leaves of Parthenium hysterophorus were collected from open fields and were identified based on morphological features and were washed and shade dried. The dried leaves were grounded and subjected for maceration extraction. A ratio of 10:100 i.e., $10 \mathrm{~g}$ of leaf powder in $100 \mathrm{ml}$ of solvent was mixed and subjected for $24 \mathrm{hrs}$ stirring. After which the mixture was filtered and the filtrate was concentrated using rotor vacuum evaporator ${ }^{18,19}$. Solvents of three different polarity was used to cover the broad range of molecules present in the sample. Methanol was used to extract highly polar molecules, while chloroform was used to extract mid-polar range of molecules and nitrogenous molecules, and finally petroleum ether was used to extract non-polar and hydrophobic molecules. The extracts were coded using the scientific name of the plant and the solvent that was used to extract the sample, i.e, Parthenium hysterophorus extracted with methanol solvent was coded as PHM, while extract with chloroform was coded as PHC and finally petroleum ether extract was labeled as PHP.

\section{Phytochemical screening}

The phytochemical screenings of different classes of secondary metabolites were performed using standard biochemical reactions ${ }^{20,21}$. The dry leaf powder and the crude extracts were subjected for the phytochemical screening.

\section{Saponin Test}

To $5 \mathrm{ml}$ of distilled water, $100 \mathrm{mg}$ of plant powder / $10 \mathrm{mg}$ of crude extract was mixed in a test tube and shaken vigorously for $1 \mathrm{~min}$. Formation of more than $1 \mathrm{~cm}$ height of froth above the water shows positive for saponin.

\section{Tannin Test}

Hundred milligram of leaf powder or $10 \mathrm{mg}$ of crude extract was dissolved in $1 \mathrm{ml}$ of distilled water, to which few drops of $5 \% \mathrm{FeCl}_{3}$ solution was added. Color change to blue or dark green indicates positive for tannins.

\section{Phenol Test}

To $1 \mathrm{ml}$ of distilled water, $100 \mathrm{mg}$ of plant powder or $10 \mathrm{mg}$ of crude extract was added and dissolved, to which $0.5 \mathrm{ml}$ of $10 \%$ Lead Acetate was added. Formation of white precipitate indicates positive for phenols.

\section{Flavonoid Test}

To $1 \mathrm{ml}$ of $10 \%$ Sulphuric acid, $100 \mathrm{mg}$ of plant powder or $10 \mathrm{mg}$ of crude extract was added and filtered after $2 \mathrm{~min}$. To $1 \mathrm{ml}$ of filtrate, $1 \mathrm{ml}$ of $1 \mathrm{M}$ $\mathrm{NaOH}$ was added. Color change to yellow indicates positive for flavonoid.

\section{Alkaloid Extract}

Either $100 \mathrm{mg}$ of plant powder or $10 \mathrm{mg}$ of crude extract was dissolved in $1 \mathrm{ml}$ of methanol. To this few drops of saturated picric acid was added. Appearance of orange to brown colored precipitate indicates positive for alkaloids.

\section{Sterols and Triterpenes}

Either $100 \mathrm{mg}$ of plant powder or $10 \mathrm{mg}$ of crude extract was dissolved in $1 \mathrm{ml}$ of chloroform. To this, few drops of Con. $\mathrm{H}_{2} \mathrm{SO}_{4}$ was added along the sides of the test tube. Formation of reddish to brown ring indicates positive for presence of sterols and triterpenes.

\section{Anthraquinone Glycosides}

Either $100 \mathrm{mg}$ of plant powder or $10 \mathrm{mg}$ of 
crude extract was dissolved in $1 \mathrm{ml}$ of chloroform. To this, $0.5 \mathrm{ml}$ of ammonia solution was added and mixed well. Appearance of reddish color indicates positive for anthraquinone glycosides.

Antibiotic Susceptibility Test (Agar-Well Diffusion Test)

Agar-Well Diffusion assay was performed to test the antagonism of the crude extracts and purified compounds against the test pathogen bacteria. Freshly prepared liquid culture of the bacteria with an optical density of 0.5 absorbance at $600 \mathrm{~nm}$ was used as inoculums for lawn culture. Sterilized cotton swabs were used to spread the inoculum on to the freshly prepared Muller Hinton Agar (MHA Hi-Media) petri plate, in which $10 \mathrm{~mm}$ wells were cut using sterile well borers. To this cut well, $100 \mu \mathrm{l}$ of test sample was added to test the antagonism. The crude extracts (PHM, PHC \& PHM) were dissolved in $10 \%$ Dimethyl Sulfoxide (DMSO) solvent for testing. In $1 \mathrm{ml}$ of $10 \%$ DMSO, $10 \mathrm{mg}$ of crude extracts were dissolved, giving a final concentration of $1 \mathrm{mg} / 100 \mu \mathrm{l}$. Each well in the MHA plates had 4 wells, with three test samples and one negative control i.e., only $10 \%$ DMSO was used to confirm the impact of the solvent/ vehicle. The pure compounds (fractions) obtained after column chromatography were also dissolved in $10 \%$ DMSO to obtain a final concentration of $10 \mu \mathrm{g} / 100 \mu \mathrm{l}$. Each well in the MHA plate contained $1 \mathrm{mg} /$ well of crude extract and $10 \mu \mathrm{g} /$ well of pure compounds respectively ${ }^{20,22}$.

\section{Test Pathogens}

The aquatic pathogens used in the study were gram-negative bacteria Vibrio harveyi (MTCC 7954) and Vibrio anguillarum (clinical isolate) were cultured in Nutrient Agar (Hi-Media) and Nutrient Broth (Hi-Media) supplemented with $2 \% \mathrm{NaCl}$ since the organisms prefer alkaline environment for optimum growth. The grampositive organisms used for comparison are Bacillus cereus (MTCC 430) and Proteus mirabilis (MTCC 425) that were cultured and maintained in Nutrient Agar (Hi-Media) and Nutrient Broth (Hi-Media) 22,23 Tamil Nadu, India and screened for its antibacterial activity against fish and shellfish pathogens. All actinomycetes isolates were screened for antibacterial activity by cross streak method against the selected fish and shellfish bacterial pathogens including Aeromonas caviae, Aeromonas hydrophila, Edwardsiella tarda,
Vibrio anguillarum and Vibrio harveyi. Secondary screening of antagonistic isolates by well diffusion method leads to the identification of potential isolate. Culture conditions for the potential isolate were optimized for maximal growth and yield of the ethyl acetate (EA).

\section{Antioxidant Potential}

The antioxidant potential of the 3 crude extracts were analyzed using $\mathrm{Fe} 3+$ reducing assay and DPPH (3.2, 2-Diphenyl-1-picrylhydrazylhydrate) assay, to identify their electron transfer potential and hydrogen transfer potential respectively.

\section{$\mathrm{Fe}^{3+}$ Reducing Assay}

The assay performed with five different concentrations of the crude extracts i.e., 25, 50, 75, $100 \& 125 \mathrm{mg} / \mathrm{ml}$ while the ascorbic acid standard was tested at much lower concentrations i.e., 0.2 , $0.4,0.6,0.8 \& 1.0 \mathrm{mg} / \mathrm{ml}$. The crude extracts were dissolved in $50 \%$ methanol for this assay. Initial reaction was performed in test tubes consisting of $2 \mathrm{ml}$ of phosphate buffer with $2 \mathrm{ml}$ of Potassium ferricyanide and $2 \mathrm{ml}$ of crude extract sample. The mixture was incubated at $50^{\circ} \mathrm{C}$ for $20 \mathrm{mins}$. To this, $2 \mathrm{ml}$ of Tri-Chloro-Acitic Acid was added followed by $0.5 \mathrm{ml}$ of $\mathrm{FeCl}_{3}(1 \%)$. The contents are mixed well for color development and the intensity of the developed color was read at $680 \mathrm{~nm}$. The observed O.D directly represents the antioxidant potential, with higher absorbance indicating higher antioxidant potential.

\section{DPPH Assay}

The assay performed with five different concentrations of the crude extracts i.e., 25, 50, 75, $100 \& 125 \mathrm{mg} / \mathrm{ml}$ while the ascorbic acid standard was tested at much lower concentrations i.e., 0.2 , $0.4,0.6,0.8 \& 1.0 \mathrm{mg} / \mathrm{ml}$. The reaction mixture consisted of $1 \mathrm{ml}$ of test sample with varying concentrations with $1 \mathrm{ml}$ of phosphate buffer and $1 \mathrm{ml}$ of DPPH $(0.3 \mathrm{mM})$ in a test tube. The contents were mixed well and incubated in dark for 30min. Then, the mixture is read for absorbance at $500 \mathrm{~nm}^{24,25}$.

\section{Silica Column Chromatography}

The chloroform extract of Parthenium hysterophorus (PHC) was subjected to silica gel column chromatography to separate the individual compounds. The column chromatography was performed using Silica Gel 60-120 mesh (SRL Pvt. Ltd.) packed to $20 \mathrm{~cm}$ height in a glass column. 
The extract ( $2 \mathrm{~g}$ of $\mathrm{PHC}$ ) was packed to the column and was eluted using varying polarity of solvent system with a flow rate of $1 \mathrm{ml} / \mathrm{min}$. Initially $100 \%$ of petroleum ether was eluted followed by $10 \%$, $20 \%, 30 \%, 40 \%, 50 \%, 60 \%, 70 \%, 80 \%$ and $90 \%$ ethyl acetate leading to $100 \%$ ethyl acetate. After reaching $100 \%$ ethyl acetate, further increase in polarity was attained using $10 \%, 20 \%, 30 \%, 40 \%$, $50 \%, 60 \% 70 \%, 80 \%$ and $90 \%$ ethanol and finally $100 \%$ ethanol was eluted. Each polarity gradient was eluted for a total volume of $100 \mathrm{ml}$ and was collected as individual fractions. The fractions were subjected for TLC analysis and fractions with similar banding pattern were pooled together and concentrated using rota-vacuum evaporator ${ }^{26-28}$.

\section{Gas Chromatography Mass Spectrometry}

The crude extracts of Parthenium hysterophorus and purified compounds were subjected for GC-MS analysis to identify molecular weight of the secondary metabolites present in it. Clarus 680 Perkin Elmer Gas Chromatography $(30.0 \mathrm{~m} \times 0.25 \mathrm{~mm} \times 250 \mu \mathrm{m})$ and mass detector turbo mass of El mode. Carrier gas used was helium at a flow rate of $1 \mathrm{ml} / \mathrm{min}$. The temperature of the injector was $200^{\circ} \mathrm{C}$ with column temperature was set at $60^{\circ} \mathrm{C}$ for $2 \mathrm{~min}$ and increased at $10^{\circ} \mathrm{C} / \mathrm{min}$ until $300^{\circ} \mathrm{C}$. The obtained molecular spectrum was matched with NIST library database to identify the secondary metabolites ${ }^{29-31}$ Saponin, Flavonoids and Terpenoids gave positive results and phlobactanins and Steriods gave negative results. In the GC-MS analysis, 26 bioactive phytechemical compounds were identified in the ethanolic extract of Aloe vera. Three different solvents such as aqueous, ethanol and acetone were used to extract the bioactive compounds from the leaves of Aloe vera to screen the antimicrobial activity selected human clinical pathogens by agar diffusion method. The maximum antibacterial activities were observed in acetone extracts $(12 \pm 0.45 \mathrm{~nm}, 20 \pm 0.35 \mathrm{~nm}$, $20 \pm 0.57 \mathrm{~nm}$ and $15 \pm 0.38 \mathrm{~nm}$.

\section{In-Silico Protein-Ligand Molecular Docking}

The protein drug targets chosen for the study were retrieved from the Protein Data Bank (https://www.rcsb.org/) with the following PDB ID: D-alanine-D-alanine ligase (2180), Dihydrofolatereductase (4LAE), Dihydropteroate Synthase (1AD4), IsoleucyltRNA Synthetase (1FFY), Penicillin Binding Protein-1b (2Y2I),
Topoisomerase-4 (2INR), Transglycosylase (3VMR). The reference standard ligand structures were downloaded from PubChem database (https://pubchem.ncbi.nlm.nih.gov/) with the following PubChem CID, Penicillin V(6869), Ciprofloxacin(2764), MLS000706879 (378385), Trimethoprim (5578), Sulfanilamide (5333), Mupirocin (446596), DB02595 (5287797), and the test ligand Sitosterol (222284). Protein-Ligand docking study was performed using AutoDockVina 1.1.2 molecular docking software was used. The retrieved protein targets were converted to macromolecules and the energy minimization of the ligands were carried out. The grid box was set based on the interacting residues of the co-crystallized ligand structures. Results of the protein-ligand interacting residues were analyzed using PyMOL software ${ }^{32-34}$.

Protein Ligand Molecular Dynamic Simulation GROMACS molecular dynamic simulation software version 2018.1-1 with 'CHARMM-36 all atom force field (2019)' was used to execute the protein-ligand complex molecular dynamic simulation (MD simulation). DHFR enzyme was chosen as the protein macromolecule, based on the molecular protein-ligand docking analysis. Trimethoprim is a known inhibitor for DHFR was used as the reference standard and the sitosterol molecule was used as test ligand. The ligand structure file was generated using the CgenFF server (https://cgenff.umaryland. edu/). Topology of the protein was generated using the CHARMM 36 all-atom force field' with recommended TIP 3P water model, stored in 'top' file format. Three individual simulations were executed for a period of 20ns (20,000ps) i.e., DHFR individually, DHFR in complex with trimethoprim and DHFR in complex with sitosterol. The results of the MD simulations were retrieved using RMSD, RMSF, and Potential energy anaylsis. The trajectory analysis of the simulation were visualized using PyMOL software ${ }^{35,36}$ biochemical, and morphological studies were performed to acquire the characteristic features of the potent isolate VITJS8. The 16Sr DNA sequencing was performed to investigate the phylogenetic relationship between the Streptomyces genera. The structure of the compound was elucidated by gas chromatography-mass spectrometry (GC-MS. 


\section{RESULTS}

\section{Extraction \& Phytochemical Classification}

Phytochemical secondary metabolites of Parthenium hysterophorus leaves were extracted using three different solvents with varying polarity and solubility properties i.e., methanol, chloroform \& petroleum ether. Methanol extract was found to have highest yield percentage among the 3 solvents. The three extracts PHM (Parthenium hysterophorus methanol extract), PHC (Parthenium hysterophorus chloroform extract), \& PHP (Parthenium hysterophorus petroleum ether extract) were subjected for biochemical reactions to understand the nature of their secondary metabolite (phytochemical) constituents. Results of the biochemical characterization of phytochemicals are tabulated in Table 1 . All 3 extracts, including the dry leaf powder sample were positive for alkaloids. Phenols were present in the chloroform and petroleum ether extracts, while the related component tannins were absent in those two extracts but was present in methanol extract and dry leaf powder. Saponin

Table 1. Phytochemical screening of crude extracts with yield percentage PHM: Methanol extract; PHC: Chloroform extract; PHP: Petroleum Ether extract

\begin{tabular}{lclll}
\hline Phytochemicals & $\begin{array}{c}\text { Leaf } \\
\text { Powder }\end{array}$ & PHM & PHC & PHP \\
& &
\end{tabular}

\begin{tabular}{lcccc}
\hline Crude extract yield & - & $18 \%$ & $6.80 \%$ & $1.40 \%$ \\
Alkaloids & + & + & + & + \\
Anthroquinone & - & - & - & - \\
Glycosides & & & & \\
Flavanoids & - & - & - & - \\
Phenols & - & - & + & + \\
Proteins & - & - & - & - \\
Reducing sugar & - & - & - & - \\
Saponin & + & - & - & - \\
Sterols / Triterpenes & + & + & + & + \\
Tannins & + & + & - & - \\
\hline
\end{tabular}

was present in significant quantity in the dry leaf powder, however, none of the 3 extracts were positive for it. Sterols and triterpenes were present in all 3 extracts and in dry leaf powder aswell. Among the various categories of phytochemical secondary metabolites, this biochemical analysis strongly suggests that, the alkaloids, sterols and triterpenes are the major classes of secondary metabolites present in the leaves and leaf extracts of Parthenium hysterophorus.

\section{Antibacterial Agar Well Diffusion Assay}

The crude extracts of Parthenium hysterophorus were subjected for antibacterial susceptibility test (AST) against 2 gram negative and 2 gram positive pathogenic bacteria. AST was performed using agar-well diffusion assay. The gram negative fish pathogens (Vibrio harveyi \& Vibrio anguillarum) were of primary interest in this study as these bacteria are aquaculture specific pathogens. Two gram-positive bacteria (Bacillus cereus and Proteus mirabilis) were also used in the study to compare the broad spectrum application of the test compounds. Results of the agar-well diffusion assay for the crude extracts are tabulated in Table 2 and the observed zoneof-inhibitions are shown in Fig. 1. Standard disc of ciprofloxacin was used as reference standard to compare the results. The chloroform extract of Parthenium hysterophorus (PHC) demonstrated

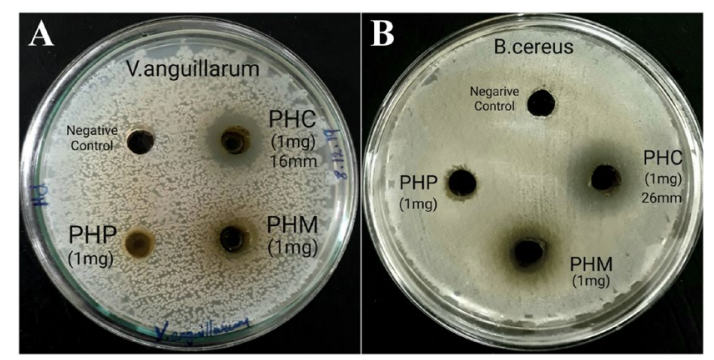

Fig.1. Antibacterial activity of Parthenium hysterophorus extracts; A: against Vibrio anguillarum; B: against Bacillus cereus.

Table 2. Results of antibacterial activity of Parthenium hysterophorus extracts

\begin{tabular}{|c|c|c|c|c|}
\hline \multirow[t]{2}{*}{ Pathogen } & PHM & $\mathrm{PHC}$ & PHP & \multirow{2}{*}{$\begin{array}{l}\text { Ciprofloxacin } \\
10 \mu \mathrm{g} / \text { disc }\end{array}$} \\
\hline & \multicolumn{3}{|c|}{$1 \mathrm{mg} /$ well } & \\
\hline Vibrio harveyi & - & $15 \mathrm{~mm}$ & - & $17 \mathrm{~mm}$ \\
\hline Vibrio anguillarum & - & $16 \mathrm{~mm}$ & - & $19 \mathrm{~mm}$ \\
\hline Bacillus cereus & - & $26 \mathrm{~mm}$ & - & $21 \mathrm{~mm}$ \\
\hline Proteus mirabilis & - & $20 \mathrm{~mm}$ & - & $21 \mathrm{~mm}$ \\
\hline
\end{tabular}


significantly strong antibacterial activity against all the 4 tested bacterial pathogens. Highest significance was demonstrated against B.cereus with maximum observed zone of inhibition (ZOI) of $26 \mathrm{~mm}$ at $1 \mathrm{mg} /$ well concentration as shown in Fig. 1. On an average PHC demonstrated significant inhibition against both the gram negative Vribrio pathogens, with $16 \mathrm{~mm}$ and $15 \mathrm{~mm}$ ZOI against Vibrio anguillarum and Vibrio harveyi respectively. The ZOI demonstrated by PHC was comparable to that of the reference standard drug. Both the methanol and petroleum ether extracts failed to show any significant ZOI. This showed that bioactive antibacterial phytochemicals are present in the chloroform extract PHC of Parthenium hysterophorus.

\section{Antioxidant Potential of P.hysterophorus}

The antioxidant potential of Parthenium hysterophorus leaf extracts were examined using $\mathrm{Fe}^{3+}$ reducing assay and DPPH assay to understand the electron transfer potential (ETP) and hydrogen transfer potential (HTP) respectively. The graphical representation of the results of antioxidant assays are shown in Fig. 3. Ascorbic acid was used as a positive standard for comparison of the results. Among the 3 extracts, PHC exhibited highest electron transfer potential, by demonstrating highest absorbance at 1.5 O.D at a concentration of $125 \mathrm{mg} / \mathrm{ml}$. However, the remaining two extracts, $\mathrm{PHM}$ and PHP also demonstrated electron transfer potential, in a dose dependent manner.

Among the 3 extracts, only PHM demonstrated significant hydrogen transfer potential in the DPPH assay, as the remaining 2 extracts $\mathrm{PHC}$ and PHP did not show any reactivity in the assay. This could suggest the presence of reducing sugars in methanol extract causing this observed reactivity in the assay.

Ascorbic acid demonstrated significantly much higher antioxidant potential in both the assays, in comparison to the Parthenium hysterophorus extracts. Hence, it can be suggested

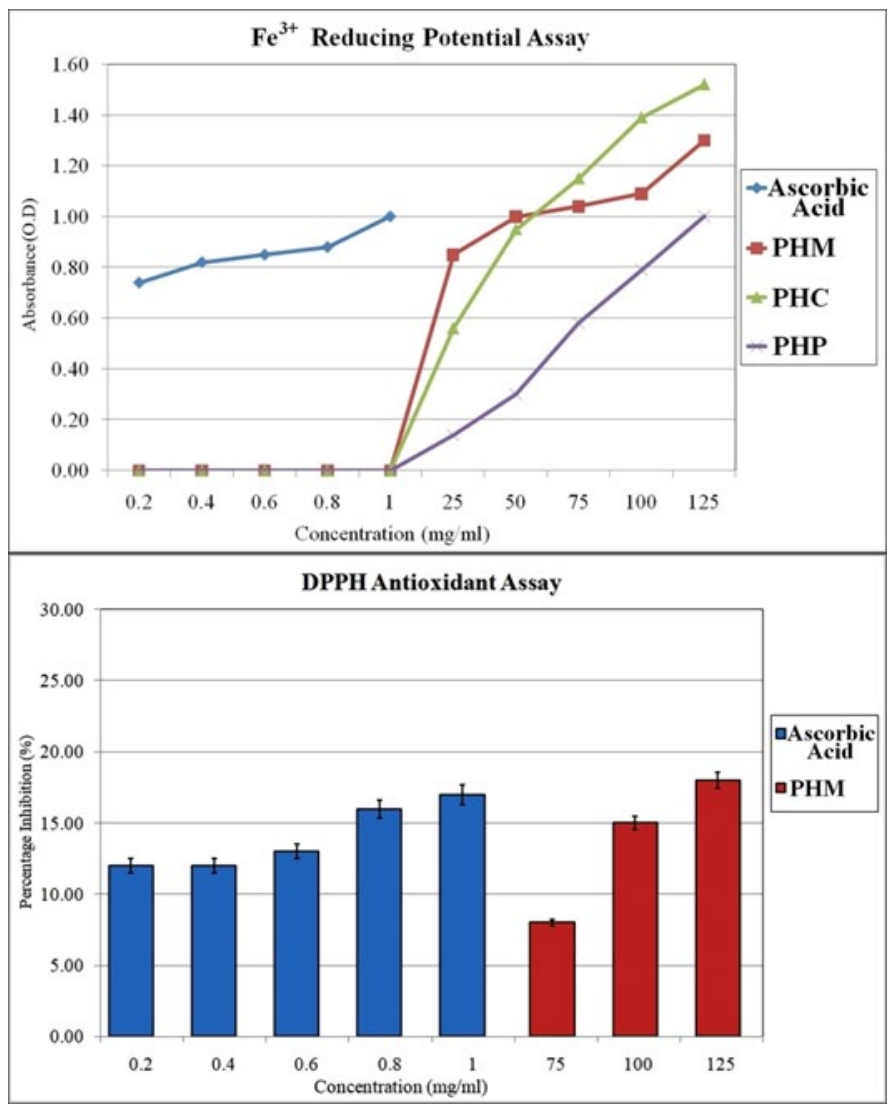

Fig 2. Antioxidant potential of Parthenium hysterophorus via $\mathrm{Fe}^{3+}$ reducing potential assay and DPPH assay 
that, P.hysterophorus is not a very effective antioxidant source. However the crude extracts demonstrated significant electron transfer potential that could be exploited in metal nanoparticle synthesis.

\section{Gas Chromatography Mass Spectrum Analysis}

The extracts of Parthenium hysterophorus were subjected for GC-MS analysis to identify the secondary metabolite phytochemicals. Each of the individual compounds detected in the gas chromatogram were investigated for their molecular weight and mass spectrum fragmentation pattern. Based on the comparison to the reported compounds of Parthenium hysterophorus, the compounds present in the crude extracts were predicted. The results of the analysis are summarised in Table 3. A total of major 15 phytochemical secondary metabolites were reported with significant quantities in literature review. Among these known secondary metabolites, a total of 4 compounds were present in PHM, 6 compounds were present in $\mathrm{PHC}$ and 3 known compounds were present in PHP extracts respectively with varying peak intesnsities. The chromatograms of GC-MS of all 3 extracts are shown in Fig. 3 (superimposed on each other). The bioactive extract PHC was subjected for TLC analysis, to study the suitable solvent system for separation and also for understanding the polarity of different phytochemicals present in the extract. In a solvent system of chloroform:ethanol (9.5:0.5 ratio) the $\mathrm{PHC}$ resolved into 8 distinct bands as shown in the image of TLC sheet analysis (Fig. 3). This TLC analysis showed that, the compounds in

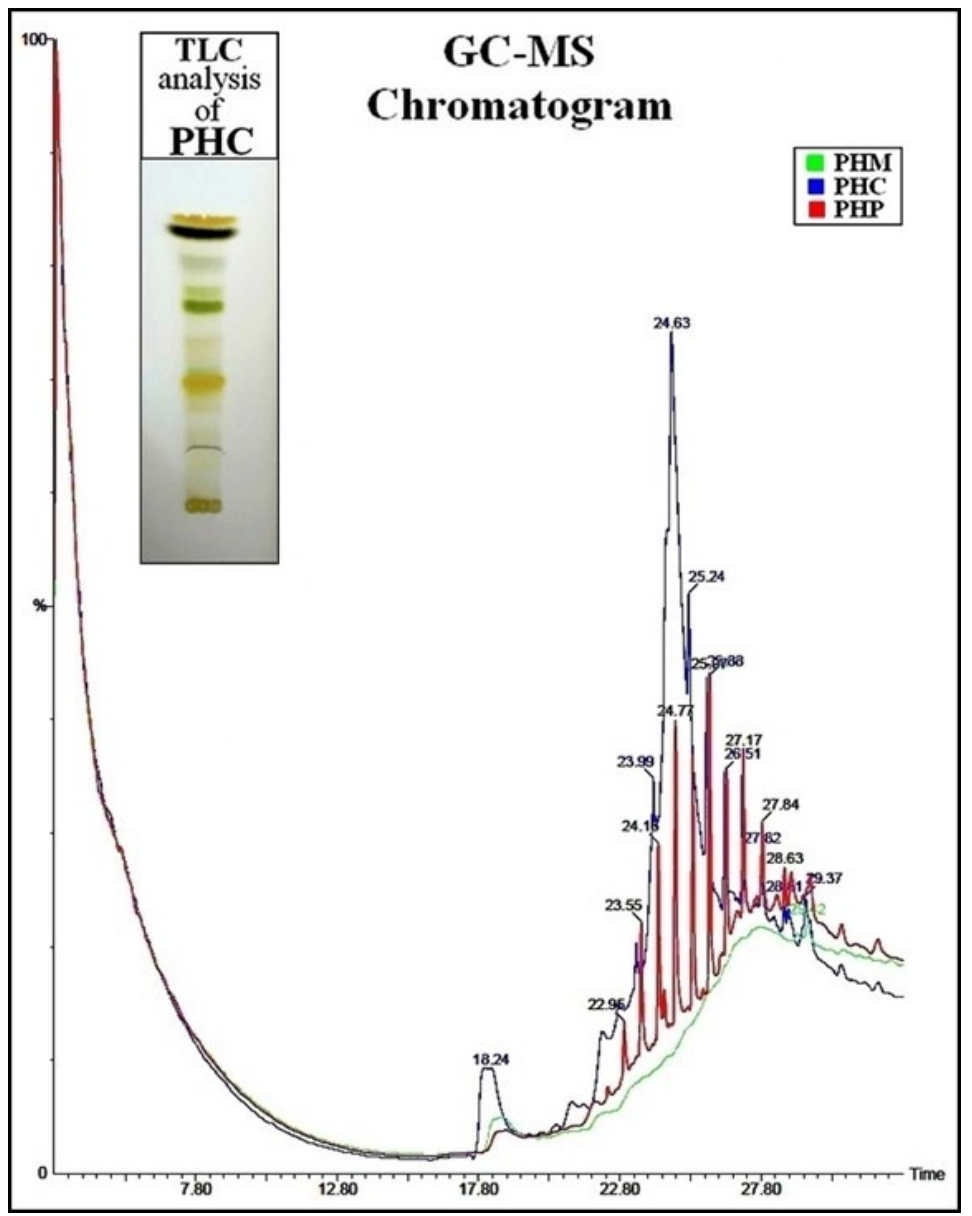

Fig. 3. Gas Chromatogram of all three extracts of Parthenium hysterophorus; TLC of chloroform extract of Parthenium hysterophorus

Journal of Pure and Applied Microbiology 
PHC extract are less polar in nature and are best to be separated with low polarity solvents in the silica gel column chromatography.

\section{Silica Gel Column Chromatography}

The chloroform extract PHC of Parthenium hysterophorus was subjected for silica gel column chromatography to separate the individual phytochemicals present in the crude extract. The column was packed to a height of $20 \mathrm{~cm}$ silica with pure petroleum ether solvent initially. The polarity of the solvent was increased in a gradient manner ( $10 \%$ at every stage). The eluted solvents were collected with $100 \mathrm{ml}$ per elution volume and eluted solvents were subjected for TLC analysis. The elutions that demonstrated similar banding pattern or similar single band were pooled together. A total of 9 different fractions, namely

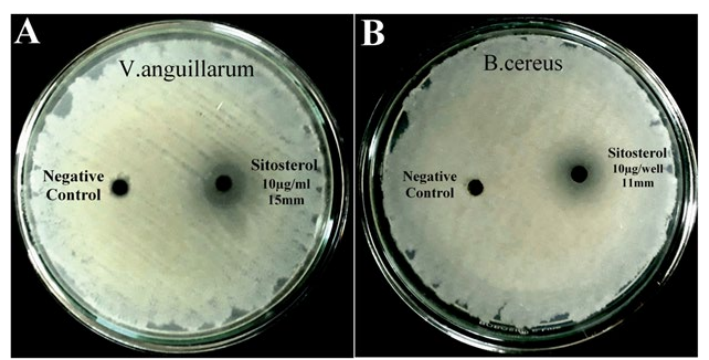

Fig. 4. Antibacterial activity of $\beta$-sitosterol; $A$ : against Vibrio anguillarum; $\mathrm{B}$ : against Bacillus cereus.
Fraction No.1, No.2, etc., were obtained from this silica gel column chromatography with unique band and banding pattern.

\section{Antibacterial Activity of Column Fractions}

All the 9 unique compound/s (fractions with unique band/banding pattern) were subjected for antibiotic susceptibility test using agar-well diffusion assay, among which only fraction No.2 showed significant antagonism against the tested bacterial pathogens. Fraction No. 2 had a single band in TLC and it is the only fraction that exhibited antagonistic activity, as shown in Fig. 4A\& Fig. 4B. The pure compound later identified to be $\beta$-sitosterol, demonstrated highest antagonism against V.anguillarum with a zone of inhibition of $15 \mathrm{~mm}$ at a concentration of $10 \mu \mathrm{g} /$ well. The $\mathrm{ZOI}$ of $\beta$-sitosterol against all the tested pathogens are tabulated in Table 4 . The activity of $\beta$-sitosterol was comparable to that of the standard drug ciprofloxacin. This compound ( $\beta$-sitosterol) was identified as the key bioactive compound in the PHC extract, since none of the other fractions demonstrated any antibacterial activity.

Identification of Bioactive Phytochemical

Fraction No.2 that demonstrated significant antibacterial activity was subjected for GC-MS analysis, to identify the molecular weight, fragmentation pattern and purity. The fraction demonstrated a single peak in the gas

Table 3. Phytochemical secondary metabolites present in crude extracts of Parthenium hysterophorus based on gas chromatography mass spectrum (GC-MS) analysis

\begin{tabular}{lcccc}
\hline Phytochemical & Mol.Wgt & PHM & PHC & PHP \\
\hline 6-Hydroxyl-Kaempferol & 302.23 & - & - & - \\
Ambrosin & 246.3 & - & $\checkmark$ & - \\
Anisic acid & 152.15 & - & - & $\checkmark$ \\
Arabinoglucoside & 596.5 & $\checkmark$ & - & - \\
Caeffic acid & 180.16 & - & $\checkmark$ & - \\
Chlorogenic acid & 354.31 & $\checkmark$ & - & $\checkmark$ \\
Fumaric acid & 116.07 & - & $\checkmark$ & - \\
Hydroxy benzoin & 212.24 & - & - & - \\
Parthenin & 262.3 & - & $\checkmark$ & - \\
P-Coumaric acid & 164.16 & - & $\checkmark$ & - \\
Quercelagetin 3,4-dimethylether & 346.3 & - & - & - \\
Sesquiterpene lactone LS-1 & 406.5 & $\checkmark$ & - & $\checkmark$ \\
Sitosterol & 414.7 & $\checkmark$ & $\checkmark$ & - \\
Tetraneurin A & 322.4 & - & - & - \\
Vanillic acid & 168.15 & - & - & - \\
$\quad$ Total No.Of Peaks & & 7 & 18 & 15 \\
& & 4 & 6 & 3 \\
\hline Journal of Pure and Applied Microbiology & & 2707 & & www.microbiologyjournal.org
\end{tabular}


chromatography analysis. In mass spectrum analysis the fraction demonstrated a highest molecular weight of $414.796 \mathrm{~g} / \mathrm{mol}$ which was matched to the known reported compounds from Parthenium hysterophorus. The molecule was also compared with the fragmentation pattern to confirm the chemical structure of the predicted molecule. The pure compound present in Fraction No. 2 was identified as $\beta$-sitosterol based on the molecular spectrum and fragmentation analysis. The exact mass of the pure compound is $414.19 \mathrm{~g} / \mathrm{mol}$ however, due to ionization in the mass spectrum observed a molecular weight of the compound was $414.718 \mathrm{~g} / \mathrm{mol}$. The mass spectrometry result of the pure compound is shown in Fig. 5.

\section{Molecular Protein-Ligand Docking}

To predict the mechanism of action of $\beta$-sitosterol's observed antibacterial activity in-silico molecular protein-ligand docking was performed. The pure compound was docked with known possible bacterial drug targets and was compared with established standard drugs that are inhibitors of the selected drug target proteins. The results of the protein-ligand docking of $\beta$-sitosterol with all protein targets and their respective

Table 4. Results of antibacterial activity of Parthenium hysterophorus extracts and pure compound

\begin{tabular}{lcc}
\hline Pathogen & $\begin{array}{c}\text { B-sitosterol } \\
10 \mu \mathrm{g} / \mathrm{ml}\end{array}$ & $\begin{array}{c}\text { Ciprofloxacin } \\
10 \mu \mathrm{g} / \mathrm{disc}\end{array}$ \\
\hline Vibrio harveyi & $9 \mathrm{~mm}$ & $17 \mathrm{~mm}$ \\
Vibrio anguillarum & $15 \mathrm{~mm}$ & $19 \mathrm{~mm}$ \\
Bacillus cereus & $11 \mathrm{~mm}$ & $21 \mathrm{~mm}$ \\
Proteus mirabilis & $10 \mathrm{~mm}$ & $21 \mathrm{~mm}$ \\
\hline
\end{tabular}

standard drugs are tabulated in Table 5. Among the 7 different proteins that were used in this analysis, $\beta$-sitosterol demonstrated highest affinity towards dihydrofolate reductase (DHFR) enzyme. This is a key enzyme in the folic acid biosynthesis and is a well proven drug target for bacterial pathogens.

Trimethoprim is a known antibacterial drug that inhibits DHFR, that demonstrated a binding affinity of $-7.40 \mathrm{Kcal} / \mathrm{mol}$ with formation of 2 hydrogen bonds. While, the test compound $\beta$-sitosterol demonstrated an outstanding -10.10 $\mathrm{Kcal} / \mathrm{mol}$ of binding affinity with formation of 1 hydrogen bond. This suggested that $\beta$-sitosterol has greater affinity to inhibit DHFR enzyme, compared to its known inhibitor. The graphical comparison of the interaction between Trimethoprim:DHFR and Sitosterol:DHFR are shown in Fig. 6. $\beta$-sitosterol is a comparatively larger molecule, and hence, it occupies greater portion of the binding pocket in DHFR leading increased interactions and better stability of the complex.

To further validate the docking results, the molecules were subjected for molecular dynamic simulations (MD simulation), to understand the interaction between the ligands and protein in real time.

\section{Molecular Dynamic Simulation}

Three different molecular dynamic simulations were executed for a period of $20 \mathrm{~ns}$ to understand the mechanism of action of $\beta$-sitosterol. First the DHFR enzyme was simulated individually to observe the protein's structural stability and flexibility. Second the enzyme DHFR was simulated in combination with trimethoprim, which is a known inhibitor of this enzyme. Finally, the enzyme DHFR was simulated in

Table 5. Results of molecular docking analysis of $\beta$-Sitosterol and potential drug targets

\begin{tabular}{|c|c|c|c|c|}
\hline Drug Targets & PDB ID & $\begin{array}{l}\text { Reference } \\
\text { Standard }\end{array}$ & $\begin{array}{c}\text { Binding } \\
\text { energy of } \\
\text { Ref. Standard } \\
\text { (Kcal/mol) }\end{array}$ & $\begin{array}{c}\text { Binding } \\
\text { energy } \\
\text { of Sitosterol } \\
\text { (Kcal/mol) }\end{array}$ \\
\hline D-alanine-D-alanine ligase & 2180 & MLS000706879 & -6.20 & -6.90 \\
\hline Dihydrofolatereductase & 4LAE & Trimethoprim & -7.40 & -10.10 \\
\hline Dihydropteroate Synthase & $1 \mathrm{AD} 4$ & Sulfanilamide & -6.40 & -6.30 \\
\hline IsoleucyltRNA synthetase & $1 \mathrm{FFY}$ & Mupirocin & -7.80 & -8.90 \\
\hline Penicillin Binding Protein $1 \mathrm{~b}$ & $2 Y 2 I$ & Penicillin V & -7.40 & -6.80 \\
\hline Topoisomerase_4 & $2 I N R$ & Ciprofloxacin & -6.70 & -7.90 \\
\hline Transglycosylase & 3VMR & DB02595 & -7.70 & -7.00 \\
\hline
\end{tabular}


complex with $\beta$-sitosterol, to compare the stability between Trimethoprim:DHFR and Sitosterol:DHFR complexes. The graphical representation of the MD simulation results are shown in Fig. 7.

\section{RMSD \& RMSF Analysis}

The Relative Mean Square Deviation (RMSD) values of the test ligand 'Sitosterol' shows a higher stability when compared to the reference drug molecule trimethoprim, suggesting a higher stability of Sitosterol-DHFR complex. The RMSD \& RMSF plot of the complexes are represented in Fig. 7.

This graph exhibits a prominent spike during the fifth nanosecond, indicative of ligand attachment followed by stabilization of the protein structure with deviations in the range of $1.0 \AA$ to $1.75 \AA$ corresponding to stable complex formation with both the ligands. Sitosterol-DHFR complex shows least RMSD value of $0.078 \mathrm{~nm}$ at $8.5 \mathrm{~ns}$ whereas trimethoprim-DHFR complex shows a least value of $0.070 \mathrm{~nm}$ at $4.0 \mathrm{~ns}$. Interaction stability was also observed with respect to the RMSF plot and all the interacting residues were in the acceptable range of $0.1-0.175 \mathrm{~nm}$. The ligands sitosterol and Trimethoprim interact at different binding pockets of the protein, Trimethoprim which is a standard DHFR inhibitor interacts with the following residues; PRO-22, TRP-23, HIS-24, THR-147, ILE-148, ARG-119, PHE-118 and PHE-17, whereas Sitosterol shows an allosteric interaction with the following residues; LEU-86, GLY-88, GLY38, HIS-39, ARG-59, PRO-87 and GLY-88.

The RMSD plot shown in Fig. 7A strongly suggests that, the protein molecule when simulated in a water environment independently shows significantly higher RMSD. The RMSD was notably lower on interaction with potential inhibitors such as Trimethoprim and Sitosterol.

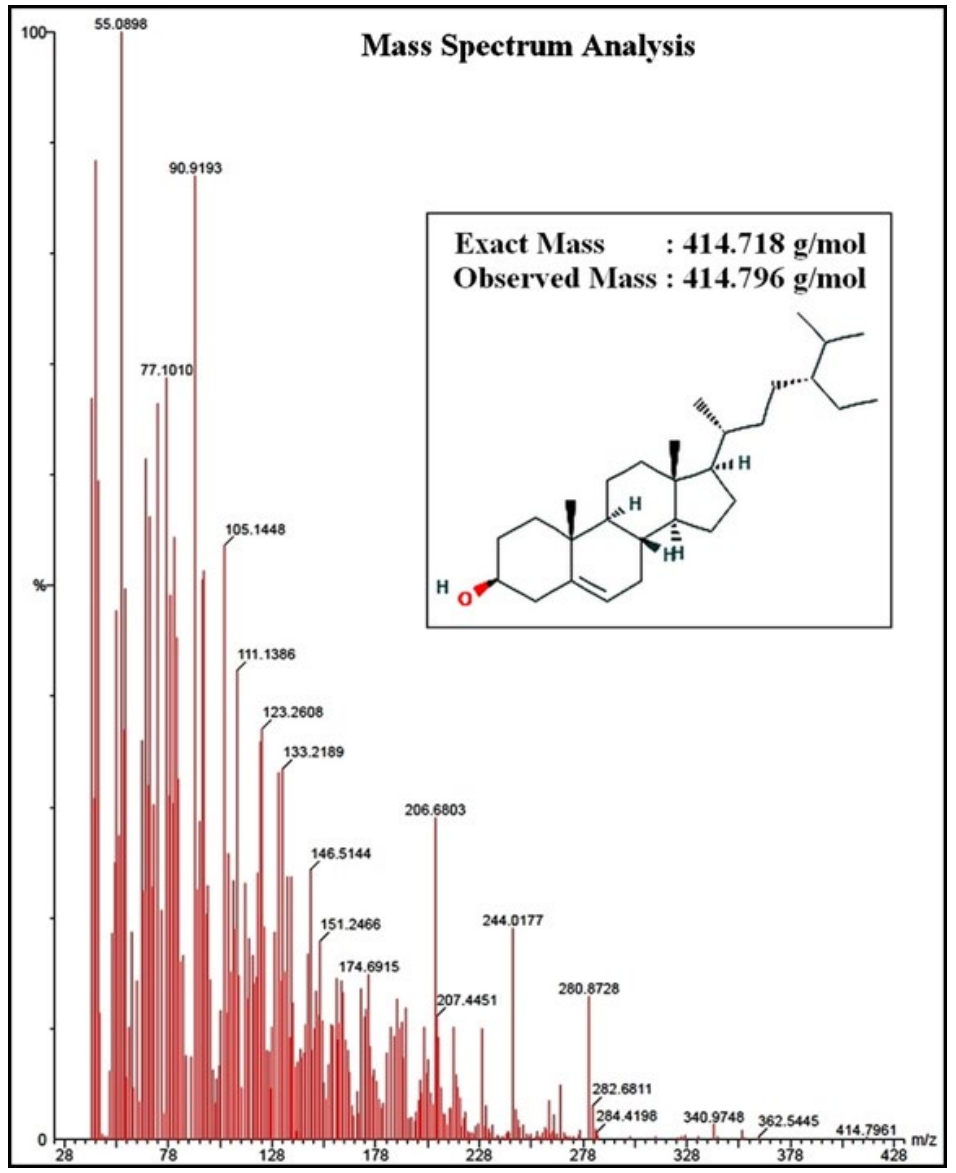

Fig. 5. Mass spectrometry analysis of pure compound that confirms its chemical structure as $\beta$-sitosterol. 
Among the test and control ligands ( $\beta$-Sitosterol and Trimethoprim), Sitosterol-DHFR complex was highly stabilized when compared to the Trimethoprim-DHFR complex. Furthermore, interactions of Sitosterol with DHFR provided greater rigidity to the protein structure hence stabilizing the complex.

The RMSF plot in Fig. 7B shows that the key residues interacting with the two ligands are strongly restricted when compared to the independent protein. This confirms the significant restriction imposed on the protein structure by the ligands suggesting them to be strong inhibitors of the DHFR protein. This directly contributes to the reduced overall RMSD of the protein-ligand complexes.

\section{Potential Energy Analysis}

Simulation of the independent protein molecule has an average potential energy of $-3.1 \times 10^{5} \mathrm{KJ} / \mathrm{Mol}$ with lowest potential energy of $-3.19 \times 10^{5} \mathrm{KJ} / \mathrm{Mol}$ at $11.3 \mathrm{~ns}$. This observed potential energy was drastically reduced on interaction with the ligands leading to the protein-ligand complex formation.

Trimethoprim in combination with DHFR demonstrated an average potential energy of $-3.8 \times 10^{5} \mathrm{KJ} / \mathrm{Mol}$ with lowest potential energy of $-3.84 \times 10^{5} \mathrm{KJ} / \mathrm{Mol}$ at $7.3 \mathrm{~ns}$ whereas Sitosterol exhibited a better stability with average potential energy of $-4.0 \times 10^{5} \mathrm{KJ} / \mathrm{Mol}$ with lowest potential energy of $-4.07 \times 10^{5} \mathrm{KJ} / \mathrm{Mol}$ observed at $6.1 \mathrm{~ns}$ during which the ligand exhibited 18 non-polar hydrophobic interactions within $3.0 \AA$. This proves the drastic decrease in the potential energy of the complex, making the protein less bioreactive leading to enzymatic inhibition of DHFR. The potential energy plot for the studied 20ns duration is shown in Fig. 7. It is observed that sitosterol:DHFR exhibits much lower potential energy than the individual protein and trimethoprim:DHFR complex. This strongly suggests that the ligand sitosterol is a potent inhibitor of DHFR enzyme.

\section{DISCUSSION}

Parthenium hysterophorus is a common weed plant, with several proven medicinal and pharmaceutical values ${ }^{6}$. One of the common values reported is its antimicrobial property, proven against Salmonella typhii, broad range of gram-positive and gram-negative clinical isolates and test pathogens $\mathrm{s}^{37-40}$ especially Staphylococcus aureus, are among the most common causes of nosocomial as well as communityacquired infections. S. aureus, a common coloniser of human skin and mucosa, can cause diseases such as skin and wound infections, urinary tract infections, pneumonia and bacteraemia (blood stream infection. This plant has not been investigated for its antagonism against aquatic pathogens, hence to the best of knowledge, this study is the first report on Parthenium hysterophorus antibacterial activity against gram-negative aquatic Vibrio species pathogens. The chloroform extract of Parthenium hysterophorus leaves demonstrated

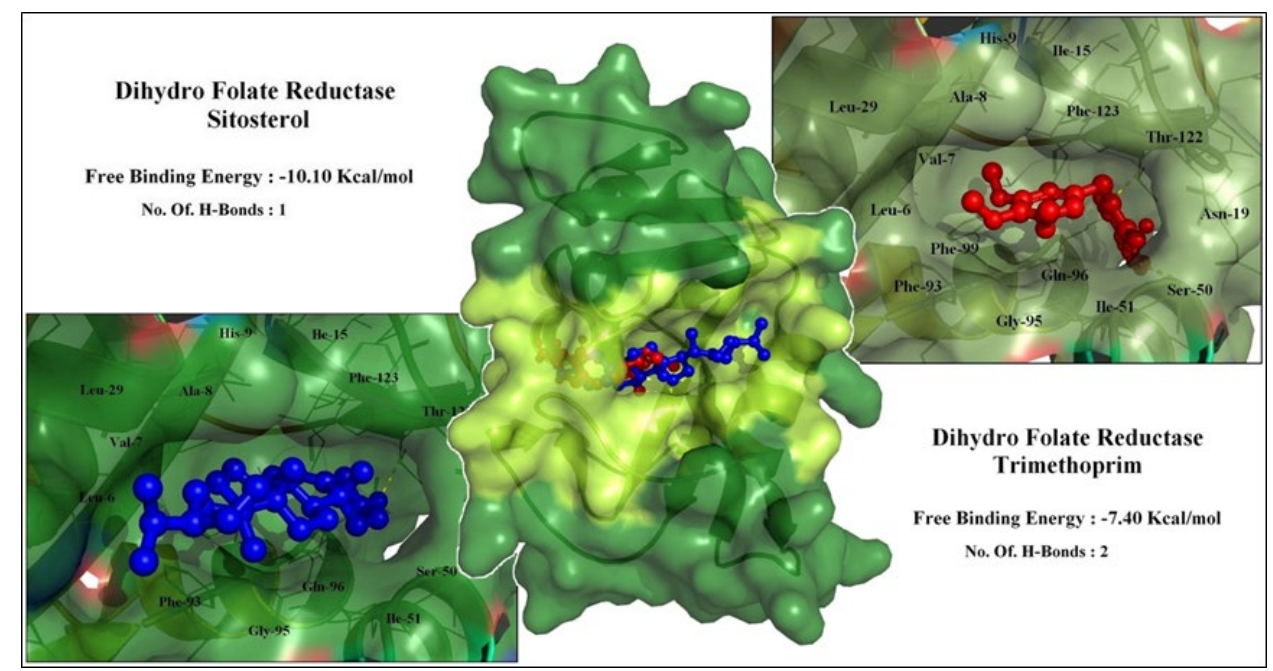

Fig. 6. Interaction between DHFR enzyme and sistosterol in comparison with trimethoprim. 
significant antagonism against gram-negative aquatic pathogens i.e., Vibro anguillarum and Vibrio harveyi, which are primary cause of aquatic infections and mortality in both cultured and wild fishes. Further, B.cereus and P.mirabilis were used to study the effect on gram-positive bacteria as

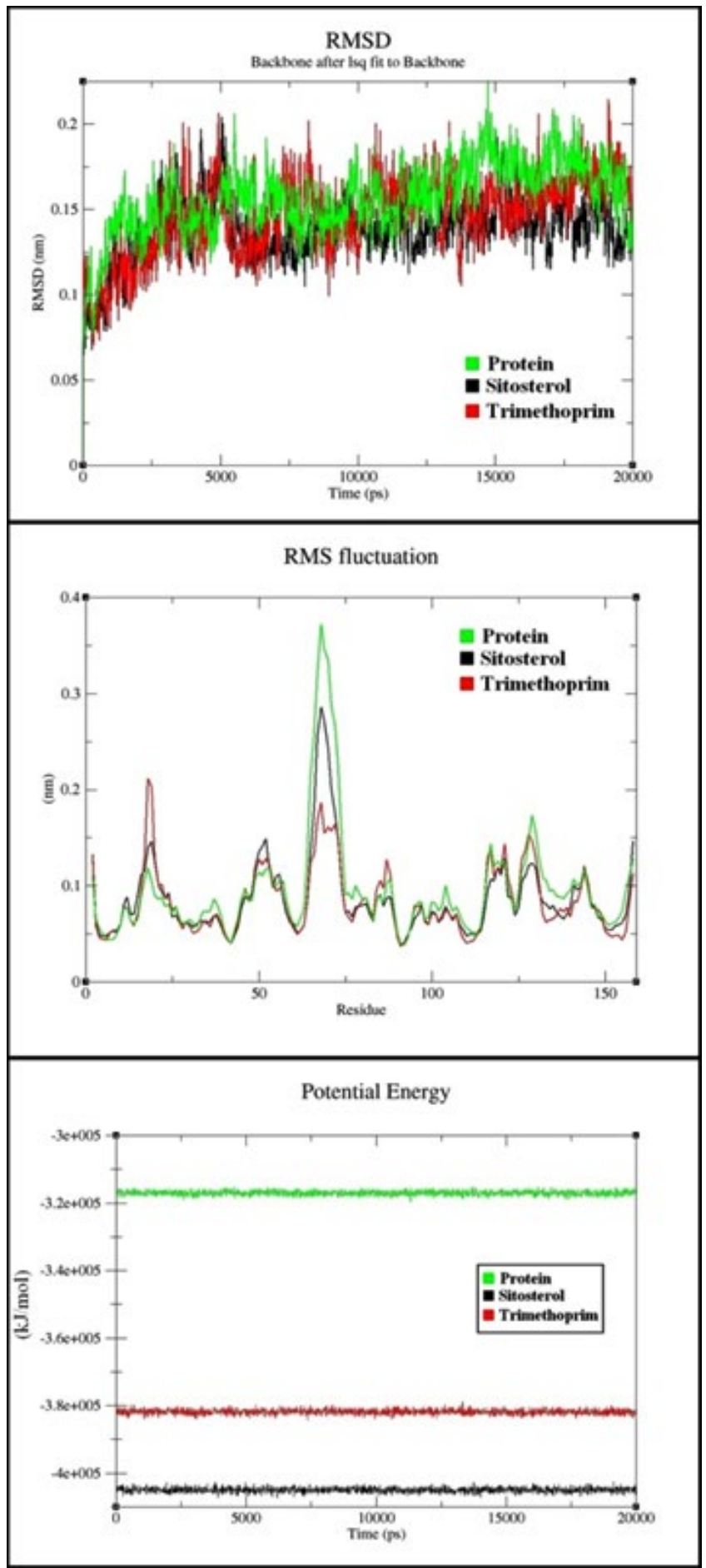

Fig. 7. RMSD, RMSF and Potential energy analysis of MD simulations 
well. The chloroform extract demonstrated strong antibacterial activity against all 4 test pathogens in this study, implying a broad spectrum antibacterial potential.

The chloroform extract (PHC) was further purified to separate the individual phytochemical secondary metabolites via silica gel column chromatography. Among the several phytochemical secondary metabolites, a total of 9 fractions with single compounds were separated, while others obtained fractions were impure and/or consisted of multiple bands. Among the 9 pure single compound fractions, only Fraction No.2 demonstrated significant antibacterial activity against the test pathogens. Based on mass spectrometry analysis in the GC-MS, the molecular weight of the pure compound was observed to be $414.76 \mathrm{~g} / \mathrm{mol}$. This molecular weight was matched to a known phytochemical 'Sitosterol' also known as ' $\beta$-Sitosterol' already reported from Parthenium hysterophorus ${ }^{41}$. To the best of knowledge, sitosterol has not been reported for antibacterial potential, and hence this is the first report to identify the phytochemical secondary metabolite sitosterol from Parthenium hysterophorus as an antibacterial compound. The compound demonstrated significant antagonism against both gram-positive and gram-negative pathogens.

To understand the mechanism of action of sitosterol for the demonstrated antibacterial activity, the molecule was subjected for proteinligand docking analysis with known bacterial drug target proteins. Among the studied interactions, sitosterol demonstrated highest inhibition potential against dihydrofolate reductase (DHFR) enzyme with a free binding energy of $-10.10 \mathrm{Kcal} /$ mol. This interaction was higher than the reference molecule trimethoprim, and hence, the proteinligand complex was subjected for GROMACS MD Simulation $^{42,43}$. DHFR is a well known antibacterial drug target, inhibition of which results in disruption of thymidylate biosynthesis and folate-dependent formyltransferases ${ }^{44}$. The simulation analysis for a period of 20ns in comparison with the known standard drug trimethoprim, confirmed that, sitosterol has higher inhibition potential to DHFR. Based on the docking analysis and MD simulation analysis, it was proposed that sitosterol exhibits antibacterial activity by inhibition of DHFR enzyme in bacteria.

Findings of this study strongly suggest that chloroform extract of Parthenium hysterophorus leaves have significant broad spectrum antibacterial activity against gram-negative aquatic pathogens and gram-positive human pathogens. The bioactive molecule in the extract was identified as sitosterol. The mechanism of action of sitosterol was predicted to be, via inhibition of DHFR enzyme using in-silico docking and MD simulations. The results suggest that the plant Parthenium hysterophorus and the phytochemical 'sitosterol' has significant potential in the field of antibacterial applications, particularly in the area of aquaculture management. However, detailed study on the toxicity and biocompatibility aspects of this plant and compound are in demand for field applications.

\section{CONCLUSION}

This study concludes that $\beta$-sitosterol isolated from Parthenium hysterophorus is a potential antibacterial phytochemical that can be applied in aquaculture management of Vibrio infections. The hydrophobicity of the molecule could be overcome by mixing with the fish feed. Further field studies are in demand to understand the ideal concentrations of usage in aquaculture plots. Use of this phytochemical as a food supplement would not only control the bacterial infections in the cultivation water bodies, but it would also increase the nutritional value of the cultured fishes, as proven by other studies.

\section{ACKNOWLEDGMENTS}

The authors thank St. Joseph's College (Autonomous), Bengaluru for supporting this research work.

\section{CONFLICT OF INTEREST}

The authors declare that there is no conflict of interest.

\section{AUTHORS' CONTRIBUTION}

All authors listed have made a substantial, direct and intellectual contribution to the work, and approved it for publication. 


\section{FUNDING}

This work was funded by Seed Money grant of St. Joseph's College (Autonomous), Bengaluru.

\section{DATA AVAILABILITY}

All datasets generated or analyzed during this study are included in the manuscript and/or the Supplementary Files.

\section{ETHICS STATEMENT}

This article does not contain any studies with human participants or animals performed by any of the authors.

\section{REFERENCES}

1. Molina AJ, Abisado RG, Calugay RJ. Bioluminescent Vibrio spp. With antibacterial activity against the nosocomial pathogens staphylococcus aureus and Klebsiella pneumoniae. AACL Bioflux. 2016;9(2):185194.

2. Austin B, Zhang $\mathrm{XH}$. Vibrio harveyi: A significant pathogen of marine vertebrates and invertebrates. Lett Appl Microbiol. 2006;43(2):119-124. doi:10.1111/ j.1472-765X.2006.01989.x

3. Gul R, Jan SU, Faridullah S, Sherani S, Jahan N. Preliminary Phytochemical Screening, Quantitative Analysis of Alkaloids, and Antioxidant Activity of Crude Plant Extracts from Ephedra intermedia Indigenous to Balochistan. Sci World J. 2017;2017:1-7. doi:10.1155/2017/5873648

4. Ahn K. The worldwide trend of using botanical drugs and strategies for developing global drugs. BMB Rep. 2017;50(3):111-116. doi:10.5483/ BMBRep.2017.50.3.221

5. Navie SC, McFadyen RE, Panetta FD, Adkins SW. The biology of Australian weeds. 27. Parthenium hysterophorus L. Plant Prot Q. 1996;11(2):7688. https://www.cabdirect.org/cabdirect/ abstract/19962301857.

6. Girish S, Harshini M, Ravi L. A Review on Pharmaceutical Potential of Parthenium Plant. Asian J Pharm. 2020;20.

7. Bhoyar MG, Gavkare OJ. Possible uses of parthenium - An agricultural waste. J Ind Pollut Control. 2014;30(2):233-236.

8. Kushwaha VB, Maurya S. Biological utilities of Parthenium hysterophorus. J Appl Nat Sci. 2012;4(1):137-143. doi:10.31018/jans.v4i1.238

9. Patel VS, Chitra V, Prasanna PL, Krishnaraju V. Hypoglycemic effect of aqueous extract of Parthenium hysterophorus L. in normal and alloxan induced diabetic rats. Indian J Pharmacol. 2008;40(4):183-185. doi:10.4103/0253-7613.43167

10. Maishi Al, Shoukat Ali PK, Chaghtai SA, Khan G. A proving of parthenium hysterophorus, L. Br Homeopath J. 1998;87(01):17-21. doi:10.1016/s00070785(98)80005-7

11. Oja V, Chen X, Hajaligol MR, Chan WG. Sublimation thermodynamic parameters for cholesterol, ergosterol, $\beta$-Sitosterol, and stigmasterol. J Chem Eng Data. 2009;54(3):730-734. doi:10.1021/je800395m

12. Wilt TJ, Ishani A, MacDonald R, Stark G, Mulrow CD, Lau J. Beta-sitosterols for benign prostatic hyperplasia. Cochrane Database Syst Rev. 1999;(2):CD001043. doi:10.1002/14651858.cd001043

13. Saeidnia S, Manayi A, Gohari AR, Abdollahi M. The Story of Beta-sitosterol- A Review. European J Med Plants. 2014;4(5):590-609. doi:10.9734/ejmp/2014/7764

14. Chai J, Kuppusamy U, Kanthimathi M. Beta-sitosterol induces apoptosis in MCF-7 cells. Malaysian J Biochem Mol Biol. 2008;16(2):28-30.

15. Gallina G, Ferretti G, Merlanti R, et al. Boldenone, boldione, and milk replacers in the diet of veal calves: The effects of phytosterol content on the urinary excretion of boldenone metabolites. J Agric Food Chem. 2007;55(20):8275-8283. doi:10.1021/jf071097c

16. Gilman $\mathrm{Cl}$, Leusch FDL, Breckenridge WC, MacLatchy DL. Effects of a phytosterol mixture on male fish plasma lipoprotein fractions and testis P450scc activity. Gen Comp Endocrinol. 2003;130(2):172-184. doi:10.1016/ S0016-6480(02)00590-7

17. Leusch FD, MacLatchy DL. In vivo implants of $\beta$-sitosterol cause reductions of reactive cholesterol pools in mitochondria isolated from gonads of male goldfish (Carassius auratus). Gen Comp Endocrinol. 2003;134(3):255-263. doi: 10.1016/ s0016-6480(03)00265-x

18. Dhanasekaranm, Abrahamgc, Mohans. The Evaluation of Pharmacological Potential on Kigelia Pinnata Dc. Int J Pharma Sci Res. 2014;5(8):489-494.

19. Thomas E, Aneesh TP, Thomas DG, Anandan R. GC-MS analysis of phytochemical compounds present in the rhizomes of Nervilia aragoana GAUD. Asian J Pharm Clin Res. 2013;6(SUPPL.3):68-74.

20. Sundar RDV, Segaran G, Shankar S, Settu S, Ravi L. Bioactivity of Phoenix dactylifera seed and its phytochemical analysis. Int J Green Pharm. 2017;11(2):S292-S297.

21. Deepa T, Elamathi R, Kavitha R, Kamalakannan, Sridhar S, Suresh Kumar J. Screening for physical, phytochemical and antimicrobial activities of leaf extracts of Sapindus emarginatus Vahl. Int J PharmTech Res. 2012;4(1):392-397.

22. Nabila MI, Kannabiran K. Antibacterial activity of soil actinomycetes against fish and shellfish pathogens. Res J Pharm Technol. 2018;11(5):19231926. doi:10.5958/0974-360X.2018.00356.6

23. Nabila MI, Kannabiran K. Antagonistic activity of terrestrial streptomyces sp. Vitnk9 against gram negative bacterial pathogens affecting the fish and shellfish in aquaculture. Rev Biol Mar Oceanogr. 2018;53(2):171-183. doi:10.22370/ rbmo.2018.53.2.1291

24. Hamad A, Arfan M, Khan SA, Fatima N, Abbasi AM, Mannan A. Evaluation of antioxidant, antimicrobial and cytotoxic potential in Artemisia vulgaris L. Rev Rom Med Lab. 2018;26(4):431-441. doi:10.2478/rrlm2018-0020

25. Blois MS. Antioxidant determinations by the use of a stable free radical. Nature. 1958;181(4617):1199- 
1200. doi:10.1038/1811199a0

26. Ravi L, Krishnan K. Benzoyloxy-ethyl-carbamic acid: A novel anticancerous secondary metabolite produced by streptomyces globosus VITLGK011. Indian J Exp Biol. 2017;55(7):411-420.

27. Saurav K, Kannabiran K. In vitro activity of 5-(2,4-dimethylbenzyl) pyrrolidin-2-one extracted from marine Streptomyces VITSVK5 spp. against fungal and bacterial human pathogens. Rev Iberoam Micol. 2012;29(1):29-33. doi:10.1016/j.riam.2011.06.008

28. Abirami M, Gopal JV, Kannabiran K. Extraction and identification of antibacterial compound from marine Streptomyces sp. VITAK1 isolated from the coast of Andaman and Nicobar Islands, India. Appl Biochem Microbiol. 2015;51(4):406-410. doi:10.1134/ S000368381504002X

29. Durga A, Mary RR. Analysis of Phytochemical Constituents And Antimicrobial Activities of Wedelia Chinensis Against Pathogens. Int J Sci Res. 2012;3(8):484-486.

30. Sharma D, Rani R, Chaturvedi M, Yadav JP. Antibacterial Capacity and Identification of Bioactive Compounds By Gcms of Allium Cepa. Int J Pharm Pharm Sci. 2018;10(2):116-121. doi:10.22159/ ijpps.2018v10i2.23698

31. Abirami M, Kannabiran K. Antibiotic potency of extract from streptomyces isolated from terrestrial soil of Amirthi forest, India. Walailak J Sci Technol. 2017;14(9Special Issue):711-721.

32. Trott O, Olson AJ. AutoDock Vina: Improving the speed and accuracy of docking with a new scoring function, efficient optimization, and multithreading. J Comput Chem. 2009;31(2):455-461. doi:10.1002/jcc.21334

33. Seeliger D, De Groot BL. Ligand docking and binding site analysis with PyMOL and Autodock/Vina. J Comput Aided Mol Des. 2010;24(5):417-422. doi:10.1007/ s10822-010-9352-6

34. DeLano WL. The PyMOL Molecular Graphics System, Version 2.0 Schrodinger LLC. 2015.

35. Naine SJ, Devi CS, Mohanasrinivasan V, Doss CGP, Kumar DT. Binding and molecular dynamic studies of sesquiterpenes (2R-acetoxymethyl-1,3,3-trimethyl-4t(3-methyl-2-buten-1-yl)-1t-cyclohexanol) derived from marine Streptomyces sp. VITJS8 as potential anticancer agent. Appl Microbiol Biotechnol. 2016;100(6):2869-
2882. doi:10.1007/s00253-015-7156-2

36. Hess B, Carsten Kutzner, David van der Spoel, Lindahl E. GROMACS 4: Algorithms for Highly Efficient, LoadBalanced, and Scalable Molecular Simulation. J Chem Theory Comput. 2008;4(3):435-447. doi: 10.1021/ ct700301q

37. Pandey AK. Anti-staphylococcal activity of a pantropical aggressive and obnoxious weed Parihenium histerophorus: An in vitro study. Natl Acad Sci Lett. 2007;30(11-12):383-386.

38. Mohsenzadeh F, Chehregani A, Amiri H. Chemical composition, antibacterial activity and cytotoxicity of essential oils of Tanacetum parthenium in different developmental stages. Pharm Biol. 2011;49(9):920926. doi:10.3109/13880209.2011.556650

39. Kumar S, Pandey S, Pandey AK. In vitro antibacterial, antioxidant, and cytotoxic activities of parthenium hysterophorus and characterization of extracts by LC-MS analysis. Biomed Res Int. 2014;2014. doi:10.1155/2014/495154

40. Krishnavignesh L, Mahalakshmipriya A, Ramesh M. In vitro analysis of phytochemical screening and antimicrobial activity of Parthenium hysterophorus L. against pathogenic microorganisms. Asian J Pharm Clin Res. 2013;6(SUPPL.5):41-44.

41. Sharma S, Gogia S, Madan H. Parthenin from Parthenium hysterophorus, its conversion to anhydroparthenin by conventional and microwave methods and their antimicrobial activity. J Indian Chem Soc. 2010;87(10):1263-1266.

42. Capasso C, Supuran CT. Sulfa and trimethoprim-like drugs-antimetabolites acting as carbonic anhydrase, dihydropteroate synthase and dihydrofolate reductase inhibitors. J Enzyme Inhib Med Chem. 2014;29(3):379387. doi:10.3109/14756366.2013.787422

43. Vinay Gopal J, Kannabiran K. Interaction of 2, 5-Di-tertbutyl-1, 4-benzoquinone with selected antibacterial drug target enzymes by in silico molecular docking studies. Am J Drug Discov Dev. 2013;3(3):200-205. doi:10.3923/ajdd.2013.200.205

44. Rao AS, Tapale SR. A study on dihdrofolate reductase and its inhibitors: A review. Int J Pharm Sci Res. 2013;4(7):2535-2547. doi:10.13040/ IJPSR.0975-8232.4(7).2535-47 